\title{
ФОРМИРОВАНИЕ ПРИВЕРЖЕННОСТИ СОТРУДНИКОВ ОРГАНИЗАЦИИ
}

\author{
Зиман Марина Алексеевна \\ магистрант \\ образовательной программы \\ «Психология менеджмента»
} Дальневосточный федеральный университет

\begin{abstract}
Аннотация: Статья посвящена проблеме повышения приверженности сотрудников организации. Выделены факторы, способствующие формированию организационной приверженности и основные подходы повышения приверженности.

В современной экономической ситуации, в условиях пандемии компаниям важно не просто функционировать, но и устойчиво развиваться, чтобы быть конкурентоспособными. Сегодня сотрудники рассматриваются в качестве фактора конкурентоспособности, а приверженность сотрудников организации как конкурентное преимущество.

Успех компании определяется профессионализмом сотрудников, сформированной внутренней установкой трудиться в конкретной организации с высокой отдачей. Сотрудники, которые привержены своим организациям, дают компаниям важные конкурентные преимущества, включая более высокую производительность труда, вовлечённость в работу, низкую текучесть кадров и т.п. Неудивительно, что организации различных размеров и типов собственности вкладывают значительные средства в повышение приверженности сотрудников организации.
\end{abstract}

Ключевые слова: Приверженный сотрудник, повышение приверженности, производительность труда, вовлеченность, мировоззрение, идентификация, организационная справедливость, моральный климат, ценности, ценностно-мотивационный профиль, мотивация труда.

\section{FORMATION OF THE EMPLOYEE COMMITMENT \\ OF THE ORGANIZATION}

Ziman Marina Alexeevna 
Abstract: The article is about of the formation of the employee commitment. The factors influencing organizational commitment and the main approaches to increasing commitment are highlighted.

In the current economic situation, in the conditions of a pandemic, it is important for companies not just to function, but to develop steadily in order to be competitive. Nowadays, employees are seen as a factor of competitiveness, and the employee commitment of the organization as a competitive advantage.

The company's success is determined by the professionalism of employees, formed internal installation to work in a particular organization with high returns. Employees who are committed to their organizations provide companies with important competitive advantages, including higher labor productivity, job engagement, low employee turnover, etc.

It is no wonder that organizations of various sizes and types of property invest significant funds to increasing the employee commitment of the organization.

Key words: Committed employee, increasing commitment, labor productivity, involvement, worldview, identification, organizational justice, moral climate, value, value-motivational profile, work motivation.

Приверженность - многокомпонентное понятие, которое включает положительное эмоционально-оценочное отношение сотрудника к выполняемой работе, трудовую мотивацию, содержание труда, достижения в работе, ценности сотрудника, удовлетворенность трудом, профессиональную этику и т.д.

Приверженный сотрудник - это вовлеченный, высокомотивированный сотрудник, он готов прилагать усилия, тратить дополнительное время, способности, энергию на достижение организационных и других целей предприятия; приверженный сотрудник готов вносить личный вклад в успех компании.

Приверженность организации - позитивное отношение сотрудника к организации и ее ценностям. Приверженный сотрудник испытывает гордость за свою организацию, он готов выйти за рамки требований работы. Приверженность проявляется в определенном поведении сотрудника.

Приверженный сотрудник:

- имеет сильное желание быть частью организации, и продолжительно работать в компании; 
- позитивно относится к коллегам и руководству, безоценочное отношение к организации;

- прилагает дополнительные усилия и вносит свой вклад, который способствует успеху компании.

- испытывает гордость за свою организацию, рекомендует её как отличное место для работы;

- мотивирован, готов прилагать много усилий, чтобы помочь своей организации добиться успеха;

- понимает свою зону ответственности и роль в компании, как она связана с общими целями, задачами и направлением его организации;

- приверженный сотрудник осознанно выполняет свою работу в организации;

- приверженный сотрудник внутреннее принимает цели и ценности организации;

- организация вдохновляет сотрудника делать свою работу лучше.

Приверженный сотрудник тратит больше сил, времени, энергии на выполнение своих рабочих обязанностей.

Приверженность также имеет и эмоциональную составляющую: сотрудник испытывает и выражает позитивные чувства по отношению к организации или человеку, перед которым он взял на себя обязательство.

И наконец, приверженность имеет «рациональный», целесообразный элемент: приверженный сотрудник сознательно решает взять на себя обязательства, он вдумчиво планирует и выполняет действия, необходимые для выполнения поставленных задач. Приверженный сотрудник охотнее берёт на себя задачи, выходящие за рамки формальной должностной инструкции.

Поскольку приверженность требует затраты времени, умственной и эмоциональной энергии, большинство сотрудников ожидают взаимности от работодателя. Взаимность влияет на уровень лояльности, т.е. работник предполагает, что в обмен на свою приверженность, он получит взамен что-то для себя ценное, например, деньги, вознаграждение, услуги, привязанность, внимание или сотрудник находит личный смысл, удовлетворение в своей работе и т.д.

В сфере труда работники и работодатели традиционно заключают «негласное» соглашение: в обмен на приверженность сотрудников, организации предоставляют работникам такие формы ценностей, например, как 
мотивационная среда компании, гарантированное рабочее место, справедливая оценка работы и труда, компенсации.

Анализ зарубежной и отечественной литературы показал, что существуют факторы, способствующие формированию организационной приверженности:

- психологический климат в коллективе, моральная и психологическая атмосфера - степень удовлетворенности работников условиями труда и количественной оценкой (зарплата, вознаграждение и т.п), возможность проявлять инициативу; доверие к руководству, достоверная информация, низкий уровень трудового стресса, положительные эмоции и т.д.

- степень вовлеченности в решение проблем организации - активное участие сотрудников в процесс принятия решений [1];

- степень информированности работников о проблемах организации, осведомлённость о решениях, затрагивающие интересы сотрудников [1];

- стиль руководства в организации - для сотрудников важны доверительные отношения с руководителем и руководством; персональная поддержка со стороны руководства, положительная линия поведения администрации.

- социальное общение в организации, групповая сплоченность сотруднику важно сохранять членство в группе, важна эмоциональная привязанность к группе, степень дружеских отношений с коллегами;

- доверие к организации - организация действует в интересах сотрудников;

- идентификация целей сотрудника с целями организации, осознание сотрудником организационных целей как собственных;

- информирование сотрудников о целях и стратегии компании [2];

- значимость содержания выполняемой работы, демонстрация важности и ценности роли специалиста для всей организации [3];

- признание и положительная обратная связь за вклад в работу.

- организационная поддержка (похвала, поддержка или одобрение), признание и положительная обратная связь за вклад в работу; значимость работы в глазах сотрудника может быть повышена, если она дает ему возможность самовыражения, позволяет почувствовать свой вклад в общий результат и требует от него достижения нового уровня знаний или профессионального мастерства [3]; 
- организационная справедливость - справедливое обращение с сотрудниками, справедливое распределение ресурсов (зарплата, продвижение по службе и пр.) [4].

Работа в компании дает сотруднику шансы расти и развиваться, он получает достаточную обратную связь о том, насколько хорошо сотрудник выполняет свою работу, компания информирует сотрудника о том, какие поощрения и за какие результаты даётся вознаграждение в компании и т.д.

Отсутствие четких критериев оценки и премирования персонала, непрозрачность системы компенсации и др. - отрицательно влияют на организационную приверженность.

Д. Шульц и С. Шульц выделяют факторы, повышающие приверженность сотрудников организации: 1) автономность труда, т. е. самостоятельность; 2) содержания работы и разнообразие труда; 3) позитивное отношение к коллективу; 4) поддержка и забота организации о сотрудниках; 5) удовлетворенность стилем руководства [5]; 6) соответствие ценностей сотрудников и организации.

Один из подходов повышения приверженности персонала соответствие ценностей: искать и отбирать для работы в организации людей, чей ценностно-мотивационный профиль соотносится с ценностномотивационным профилем компании. В последнее время все больше работодателей осознают, что у сотрудников должны быть ценности, ценностные ориентации, соответствующие ценностям компании. Более высокий уровень приверженности к организации будет у тех сотрудников, ценности которых совместимы с ценностями организации.

Если работники не разделяют ценности и миссию организации, ценностей труда в данной организации, то такие сотрудники чаще всего пренебрежительно относятся к своим профессиональным обязанностям.

Сотрудник поступает исходя из своей индивидуальной системы ценностей, опираясь на свой жизненный опыт. Успех компании возможен, если все работники от руководителя до линейных сотрудников — это коллектив единомышленников, который имеет сходные индивидуальные системы ценностей. Ценностные приоритеты должны согласовываться от самого верха организационной структуры до каждого конкретного сотрудника — это приводит к формированию коллектива единомышленников, т. к. все сотрудники руководствуются одной и той же системой ценностей [6]. 
Если сотрудники разделяют ценности компании - это лучший фундамент для формирования приверженности самого высокого уровня.

Противоположный подход — мотивация труда и трудовые ценности: мотивировать и стимулировать деятельность персонала; организация целенаправленно предпринимает действия для развития приверженности сотрудников организации.

Приверженность можно повысить путём материальных и нематериальных методов. Материальные методы стимулирования приверженности: материальные вознаграждения; участие в прибыли компании; предоставление займов, льготное кредитование; оплата обучения, тренингов; социальный пакет, дополнительное медицинское страхование; оплата услуг мобильной связи, тренажерных залов и т.д.

Нематериальные методы повышения приверженности: комфортная рабочая среда; корректное отношение к персоналу со стороны руководства организации; признание и одобрение результатов работы, похвала, поддержка, значимость занимаемой должности; обучение персонала и т.д.

Развитие профессиональных навыков и знаний, профессиональная перспектива и самореализация сотрудника, карьерный рост, возможность творческого и делового роста - формируют высокую приверженность сотрудников организации.

Таким образом, приверженный сотрудник имеет сильное желание быть частью организации, и продолжительно работать в компании; он позитивно относится к коллегам и руководству и прилагает дополнительные усилия, вносит свой вклад в успех компании.

Приверженный сотрудник испытывает гордость за свою организацию, рекомендует её; он мотивирован, разделяет цели и ценности компании; организация вдохновляет сотрудника делать свою работу лучше.

Отметим, что анализ зарубежной и отечественной литературы по проблеме приверженности сотрудников организации показал, что выделяют факторы, формирующие организационную приверженность: возможности, которые созданы в организации для удовлетворения основных потребностей сотрудников, моральный климат в коллективе, вовлеченность сотрудника в организацию, информированность работников, идентификация целей сотрудника с целями организации, значимость содержания выполняемой работы для сотрудника и т.д. 
При изучении проблемы повышения приверженности сотрудников организации выделяют следующие основные подходы: 1) поиск и отбор сотрудников для организации, чей ценностно-мотивационный профиль соотносится с ценностно-мотивационным профилем компании, где сотрудники разделяют ценности компании и 2) мотивировать и стимулировать деятельность персонала; организация целенаправленно развивает приверженность сотрудников.

\section{Список литературы}

1. S. Lipatov, K. Sinchuk Social-psychological factors of commitment of employees of the organization // Organizational Psychology. - 2015. - № 4. C. 6-28.

2. Магура М. И., Курбатова М. Б. Секреты мотивации, или Мотивация без секретов // Управление персоналом. - 2007. - №13. - С. 11

3. Полосухина М. В. Формирование модели управления лояльностью персонала современной организации // Управление экономическими системами: электронный журнал. - 2011. - №12 (36). - С. 117

4. Мотивирующая организация труда (М. Магура, М. Курбатова, "Управление персоналом", N 13-14, июль 2007 г.)

5. Беляева, Т. А. Взаимосвязь организационной культуры и приверженности сотрудников банковской сферы: маг.дис. ...:37.04.01: защищена 12.07.18 / Т. А. Беляева. — Москва: НИУ ВШЭ, — $2018-104$ с.

6. Шульц Д., Шульц С. Психология и работа. - 8-е изд. - СПб.: Питер, 2003. $-334 \mathrm{c}$.

7. Харский К. В. На стороне клиента. - СПб.: Буки Веди, - 2021. - 407 с. 